\title{
Physiological mechanisms of emotional intelligence in operators with different work efficiency
}

\author{
Rodion A. Kudrin ${ }^{1}$, \\ Elena V. Lifanova ${ }^{2}$ \\ Department of Normal \\ Physiology, Volgograd \\ State Medical University \\ VolgSMU \\ Volgograd, Russian \\ Federation \\ 1rodion.kudrin76@yande \\ x.ru, \\ 2e.v.lifanova@mail.ru
}

\author{
Nikolai N. Sentiabrev \\ Department of Anatomy \\ and Physiology, \\ Volgograd State Physical \\ Education Academy \\ VSPEA \\ Volgograd, Russian \\ Federation \\ nnsvgsp@rambler.ru
}

\author{
Maksim N. Dyatlov \\ Department of \\ Descriptive Geometry \\ and Computer Graphics, \\ Volgograd State \\ Technical University \\ VSTU \\ Volgograd, Russian \\ Federation \\ makdyatlov@yandex.ru
}

\author{
Mikhail Y. Budnikov \\ Department of Normal \\ Physiology, \\ First Moscow State \\ Medical University \\ FMSMU \\ Moscow, Russian \\ Federation \\ m.y.budnikov@gmail.c \\ om
}

\begin{abstract}
In this work it is shown that the effectiveness of operator's activities is higher in individuals with medium emotional intelligence than in those with low emotional intelligence. It is achieved due to the greater expression of the alpha rhythm for $69 \%$ in amplitude and for $78 \%$ in the index, low-frequency beta-rhythm amplitude for $50 \%$, lower expression of the delta-rhythm in the index for $22 \%$ at rest. In addition, the group with medium emotional intelligence compared to the group with low emotional intelligence demonstrates $10.5 \%$ higher ability for emotional assessment of faces, $8.9 \%$ more developed ability to understand emotional transitions, $13.6 \%$ better ability for emotional assessment of the images and $75.9 \%$ higher ability to describe their emotional state.
\end{abstract}

Keywords-emotional intelligence, operators' work, work efficiency, physiological mechanisms, bioelectrical activity of brain.

\section{INTRODUCTION}

A steady increase in the pace of technological progress, the increasing role of automated control systems in various industries, a significant increase in the volume of information, analyze control personnel, leads to the inevitable increase in the burden on operators in the system "manmachine", and, as a consequence, to tighten the requirements imposed on operators. In these conditions the special urgency is acquired, the optimization of operators' labor in general, and different ways of impact of information on decisions taken by the man, his work and behavior in particular. In this regard, currently, the development of psychophysiological aspects of the problem of increasing the efficiency and reliability operators' work is one of the main directions of engineering psychology and physiology of labor $[1,2,3]$.

There is an urgent need for detailed analysis not only of the external technical means of optimization of operator's activities, but also focused on the human part of the system of psychophysiological means. Thus, to the fore comes the search for new highly informative criteria, allowing to optimize the professional orientation and professional selection of persons to perform operator's work [4]. In our opinion, the high level of emotional intelligence (EI, EQ) can be such a suitable criterion.

The choice of this criterion is due to the fact that the work of the human operator, like any other activity, is emotionally charged and emotionally dependent, because the emotional background is closely linked to motivational and volitional spheres. In addition, emotional intelligence is the ability of a person to critically analyze emotions, thoughts, motives and, consequently, is the capacity for purposeful management of behavior. Emotional intelligence is the understanding of the emotional and motivational sphere of others, the ability to manage their emotions and predict behavior, and, therefore, is the capacity for optimal management of the labor process.

In this case it is possible and expedient use of the concept of emotional intelligence as the basis for assessing and forecasting the impact of operator performance in different conditions and for a detailed study of the physiological provision of personnel.

\section{GOAL}

The goal of the current research is to study the degree of emotional intelligence influence and its individual components, as well as bioelectrical activity influence on the brain performance of a man-operator.

\section{MATERIALS AND METHODS}

The meeting was attended by 31 participants: 9 (29\%) males and $22(71 \%)$ females. At the time of inclusion in the study all participants were aged from 18 to 26 years. This age gap relates to the time when career choice is made. According to the results of the medical examination, all participants were deemed healthy.

All study participants had only basic skills of operator activity of the sensory profile.

To achieve the goals of this research the following methods were used: 
1) electroencephalography (EEG) 1 - international scheme of installation of electrodes "10-20\%" was used) [5];

2) simulated operator activity [6];

3) test of emotional intelligence (EQ-test) [7].

Modeling of operator activity was made with the help of original computer program "Smile" v. 1.3 [6].

This program allows you to evaluate the effectiveness of operations, senso-motor tracking for three periods (duration of each period of 3 minutes), which vary in speed and degree of randomness of the movement of the cursor, target, and duration. Each subsequent study period was characterized by the increasing complexity of tasks. The delay in the movement of the cursor for a first period of testing was $200 \mathrm{~ms}$, the second $-100 \mathrm{~ms}$, and the third $-50 \mathrm{~ms}$. The randomness in the movement of the cursor for a first period of testing was 100 , for the second - and the third for $1000-10000$ conventional units.

Methods of operations research senso-motor tracking consisted of the following (model of operator activity): on a black background monitor screen was moving a white cursor size in one participant is offered as quickly as possible and to accurately match on-screen cursor manipulator (mouse) moving around the screen object. Before testing, all subjects were instructed in detail about the upcoming mission, and within 10 minutes had the opportunity to work out in its execution. When testing the tracking duration was 9 minutes, which is sufficient for the adaptation to the examinee performed the task.

For each subject in each period of the test program was carried out to record all the values of the distance between the moving object and the cursor of the manipulator - this distance was measured on each cycle of movement of the object in millimeters. The program also calculated the average values of this parameter for each period and the whole test in general.

\section{RESULTS AND DISCUSSION}

According to the results of the EQ-test all participants were divided into three groups: low $\mathrm{EQ}$ (if $\mathrm{EQ}<\mathrm{M}-\sigma$ ), mid $\mathrm{EQ}$ (if $\mathrm{M}$ $\sigma \leq \mathrm{EQ} \leq \mathrm{M}+\sigma$ ), high $\mathrm{EQ}$ (if $\mathrm{EQ}>\mathrm{M}+\sigma$ ). Next, we evaluated the parameters of the structure of emotional intelligence in selected groups with validation of differences. The distribution of the analyzed sample differed from the normal one (based on the values of kurtosis and asymmetry), and that's why the nonparametric Mann-Whitney U-criterion was used (table 1).

TABLE I. THE STRUCTURAL PARAMETERS OF THE EQ IN GROUPS WITH DIFFERENT EMOTIONAL INTELLIGENCE (U-MANN-WHITNEY TEST)

\begin{tabular}{|l|c|c|c|}
\hline \multirow{2}{*}{$\begin{array}{l}\text { EQ structure } \\
\text { parameters }\end{array}$} & \multicolumn{3}{|c|}{ EQ groups } \\
\cline { 2 - 4 } & $\begin{array}{c}\boldsymbol{L o w} \boldsymbol{E Q} \\
\boldsymbol{M} \pm \boldsymbol{m}(\boldsymbol{n}=\mathbf{5})\end{array}$ & $\begin{array}{c}\text { Mid } \mathbf{E Q} \\
\boldsymbol{M} \pm \boldsymbol{m}(\boldsymbol{n}=\mathbf{2 4})\end{array}$ & $\begin{array}{c}\text { High } \boldsymbol{E Q} \\
\boldsymbol{M} \pm \boldsymbol{m}(\boldsymbol{n}=\mathbf{2})\end{array}$ \\
\hline $\begin{array}{l}\text { Emotional evaluation } \\
\text { of faces }\end{array}$ & $0.38 \pm 0.021^{\mathrm{a}}$ & $0.42 \pm 0.012$ & $0.41 \pm 0.046$ \\
\hline $\begin{array}{l}\text { Ability to recognize } \\
\text { emotions, which } \\
\text { effectively facilitate } \\
\text { specific activities }\end{array}$ & $0.30 \pm 0.037$ & $0.33 \pm 0.011$ & $0.30 \pm 0.036$ \\
\hline $\begin{array}{l}\text { The ability to } \\
\text { understand the } \\
\text { transitions of } \\
\text { emotions, }\end{array}$ & $0.45 \pm 0.012^{\mathrm{a}}$ & $0.49 \pm 0.011$ & $0.44 \pm 0.006$ \\
\hline
\end{tabular}

\begin{tabular}{|c|c|c|c|}
\hline \multirow{2}{*}{$\begin{array}{l}\text { EQ structure } \\
\text { parameters }\end{array}$} & \multicolumn{3}{|c|}{ EQ groups } \\
\hline & $\begin{array}{c}\operatorname{Low} E Q \\
M \pm m(n=5)\end{array}$ & $\begin{array}{c}\text { Mid EQ } \\
M \pm m(n=24)\end{array}$ & $\begin{array}{c}\text { High EQ } \\
M \pm m(n=2)\end{array}$ \\
\hline \multicolumn{4}{|l|}{$\begin{array}{l}\text { mechanisms of their } \\
\text { variability and the } \\
\text { flow of emotions in } \\
\text { time }\end{array}$} \\
\hline $\begin{array}{l}\text { Ability to regulate } \\
\text { own emotional states }\end{array}$ & $0.34 \pm 0.020$ & $0.35 \pm 0.008$ & $0.37 \pm 0.044$ \\
\hline $\begin{array}{l}\text { Emotional } \\
\text { assessment of the } \\
\text { images }\end{array}$ & $0.44 \pm 0.016^{\mathrm{a}}$ & $0.50 \pm 0.014$ & $0.42 \pm 0.170$ \\
\hline $\begin{array}{l}\text { Ability of a person to } \\
\text { describe his or her } \\
\text { emotional state }\end{array}$ & $0.29 \pm 0.046^{\mathrm{a}}$ & $0.51 \pm 0.009$ & $0.48 \pm 0.070$ \\
\hline $\begin{array}{l}\text { Ability to distinguish } \\
\text { mixed and complex } \\
\text { feelings and to } \\
\text { understand the } \\
\text { interactions of } \\
\text { emotions }\end{array}$ & $0.47 \pm 0.038$ & $0.52 \pm 0.008$ & $0.51 \pm 0.005$ \\
\hline $\begin{array}{l}\text { Ability to regulate } \\
\text { emotional states of } \\
\text { other people }\end{array}$ & $0.34 \pm 0.041$ & $0.34 \pm 0.009$ & $0.44 \pm 0.020$ \\
\hline Final EQ-test result & $0.38 \pm 0.013^{\mathrm{a}}$ & $0.47 \pm 0.005^{\mathrm{b}}$ & $0.53 \pm 0.010$ \\
\hline
\end{tabular}

As follows from table 1, the main differences in the parameters of the structure of emotional intelligence were found between the groups with medium and low EQ. In particular, the ability for emotional evaluation of persons in the group with medium EQ was $10.5 \%$ higher than in the low EQ group $(p<0.05)$. The ability to understand the transitions of emotions, mechanisms of their variability and the flow of emotions in time in the group with average EQ was $8.9 \%$ higher than in the low EQ group $(\mathrm{p}<0.05)$. Emotional assessment of the images in the group with medium EQ was $13.6 \%$ higher than in the low EQ group $(\mathrm{p}<0.05)$. The ability of a person to describe his or her emotional state in the group with medium EQ was $75.9 \%$ higher than in the low EQ group $(p<0.05)$. The overall level of emotional intelligence in the average EQ group was $23.7 \%$ higher than in the group with low EQ and in high EQ group it was $12.8 \%$ higher than in the average EQ group $(\mathrm{p}<0.05)$.

Next, we estimated the bioelectrical brain activity in the selected groups of emotional intelligence (table 2).

TABLE II. PARAMETERS OF EEG ACTIVITY IN GROUPS WITH DIFFERENT EMOTIONAL INTELLIGENCE (U-MANN-WHITNEY TEST)

\begin{tabular}{|c|c|c|c|c|}
\hline \multirow{2}{*}{\multicolumn{2}{|c|}{ EEG parameters }} & \multicolumn{3}{|c|}{ EQ groups } \\
\hline & & \multirow{2}{*}{$\begin{array}{c}\text { Low } E Q \\
M \pm m(n=5)\end{array}$} & \multirow{2}{*}{$\begin{array}{c}\begin{array}{c}\text { Mid EQ } \\
M \pm m \\
(n=24)\end{array} \\
9.9 \pm 0.12\end{array}$} & \multirow{2}{*}{$\begin{array}{c}\boldsymbol{H i g h} \boldsymbol{E Q} \\
\boldsymbol{M} \pm m(n=2)\end{array}$} \\
\hline \multirow{3}{*}{$\begin{array}{l}\text { Alpha- } \\
\text { rhythm }\end{array}$} & $\begin{array}{l}\text { frequency, } \\
\mathrm{Hz}\end{array}$ & & & \\
\hline & $\begin{array}{l}\text { amplitude, } \\
\mu \mathrm{V}\end{array}$ & $1.3 \pm 0.10^{\mathrm{a}}$ & $2.2 \pm 0.18$ & $2.2 \pm 0.35$ \\
\hline & index, $\%$ & $11.4 \pm 1.66^{\mathrm{a}}$ & $20.3 \pm 2.23$ & $10.6 \pm 2.85$ \\
\hline \multirow{2}{*}{$\begin{array}{l}\text { Beta- } \\
\text { rhythm } \\
(\mathrm{LF})\end{array}$} & $\begin{array}{l}\text { frequency, } \\
\mathrm{Hz}\end{array}$ & $14.4 \pm 0.85$ & $15.0 \pm 0.21$ & $18.6 \pm 2.35$ \\
\hline & $\begin{array}{l}\text { amplitude, } \\
\mu \mathrm{V}\end{array}$ & $0.6 \pm 0.11^{\mathrm{a}}$ & $0.9 \pm 0.08$ & $0.8 \pm 0.30$ \\
\hline
\end{tabular}




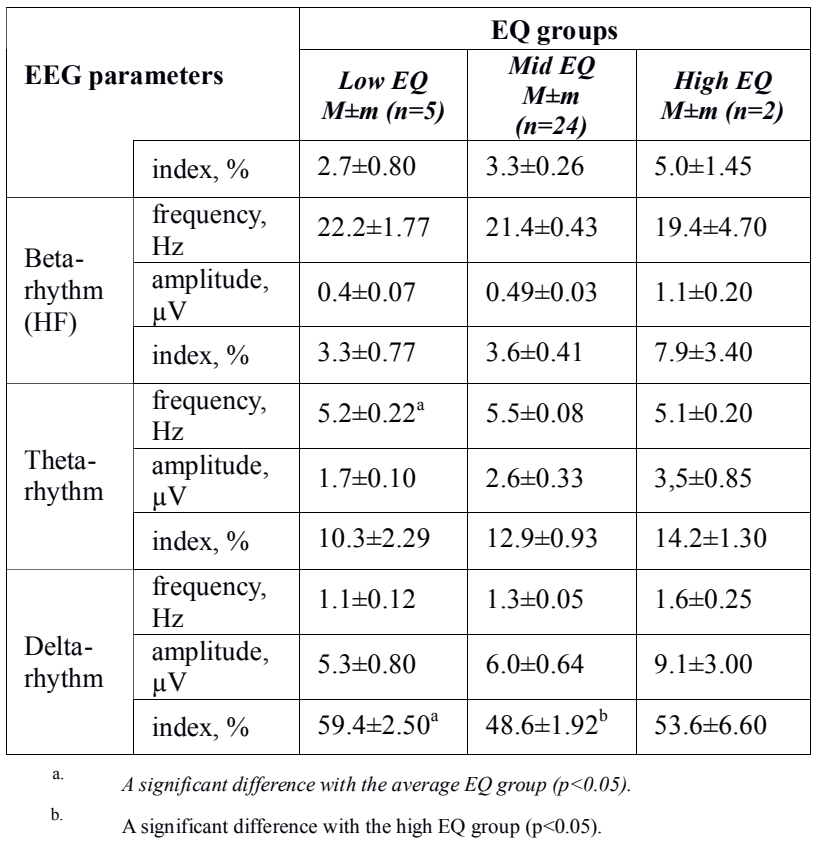

As follows from table 2, the main differences in the parameters of brain bioelectrical activity was discovered between the groups with average and low emotional intelligence. In particular, the severity of the alpha rhythm in the group with medium EQ was $69 \%$ higher in amplitude and $78 \%$ higher in the index $(\mathrm{p}<0.05)$ than in the group with low EQ.

The severity of low-frequency beta-rhythm in the group with medium EQ was $50 \%$ higher in amplitude $(\mathrm{p}<0.05)$ than in the group with low EQ.

The severity of the theta rhythm in the group with medium EQ was $5.8 \%$ higher in frequency $(p<0.05)$ than in the group with low EQ.

The severity of the Delta rhythm index in the average EQ group was $22 \%$ lower than in the group with low EQ and 10.3 $\%$ lower than in the group with high EQ $(\mathrm{p}<0.05)$.

Next, we have evaluated the effectiveness of the simulated operator activity in selected groups of emotional intelligence (table 3).

TABLE III. THE PARAMETERS OF THE SIMULATED OPERATOR ACTIVITY IN GROUPS WITH DIFFERENT EMOTIONAL INTELLIGENCE (U-MANN-WHITNEY TEST)

\begin{tabular}{|l|l|l|l|}
\hline \multirow{2}{*}{$\begin{array}{l}\text { Operators work } \\
\text { parameters }\end{array}$} & \multicolumn{3}{|c|}{ EQ groups } \\
\cline { 2 - 4 } & $\begin{array}{c}\text { Low EQ } \\
\boldsymbol{M} \pm \boldsymbol{m}(\boldsymbol{n}=5)\end{array}$ & $\begin{array}{c}\text { Mid } \boldsymbol{E Q} \\
\boldsymbol{M} \pm \boldsymbol{m}(\boldsymbol{n}=\mathbf{2 4})\end{array}$ & $\begin{array}{c}\text { High } \boldsymbol{E Q} \\
\boldsymbol{M} \pm \boldsymbol{m}(\boldsymbol{n}=\mathbf{2})\end{array}$ \\
\hline $\begin{array}{l}\text { 1 st tracking period, } \\
\text { misalignment in mm }\end{array}$ & $0.6 \pm 0.12^{\mathrm{a}}$ & $0.4 \pm 0.12$ & $0.4 \pm 0.21$ \\
\hline $\begin{array}{l}\text { 2nd tracking period, } \\
\text { misalignment in mm }\end{array}$ & $1.5 \pm 0.06$ & $2.4 \pm 0.99$ & $2.4 \pm 1.07$ \\
\hline $\begin{array}{l}\text { 3rd tracking period, } \\
\text { misalignment in mm }\end{array}$ & $5.9 \pm 0.38$ & $5.5 \pm 0.24$ & $7.6 \pm 1.13$ \\
\hline $\begin{array}{l}\text { Average result of } \\
\text { three periods, } \\
\text { misalignment in mm }\end{array}$ & $3.8 \pm 0.21$ & $3.7 \pm 0.21$ & $4.7 \pm 0.96$ \\
\hline
\end{tabular}

A significant difference with the average EQ group $(p<0.05)$.
As follows from table 3, the main differences in the parameters of the simulated operator activity were detected between the groups with average and low emotional intelligence. In particular, the efficiency of the operator's activities in models of senso-motor tracking was 33\% higher in medium EQ group compared to the low EQ group while performing initial difficulty tasks $(p<0.05)$. Differences between groups were unreliable in the tasks of medium and high complexity.

\section{CONCLUSIONS}

1. In individuals with average emotional intelligence the effectiveness of simulated operator activity was significantly higher than in those with low emotional intelligence. It is achieved by $69 \%$ greater severity of the alpha rhythm in amplitude at rest and $78 \%$ in the index, by $50 \%$ greater lowfrequency beta-rhythm amplitude, by $22 \%$ lower expression of Delta-rhythm in the index.

2. The structure of emotional intelligence in the group with medium EQ compared to the low EQ group is characterized by $10.5 \%$ higher ability for emotional assessment of individuals, by $8.9 \%$ more developed ability to understand the transitions of emotions, $13.6 \%$ better ability for emotional assessment of the images, and $75.9 \%$ higher ability to describe their emotional state.

3. Identified typological differences of physiological and psychophysiological components of effective operators allow us to assert that emotional intelligence, as a dynamic yet relatively stable structure in the system of human abilities, has a decisive influence on the level of success of a human operator's work.

\section{REFERENCES}

[1] Yu. K. Strelkov, "Engineering and professional psychology," 2nd ed, erased., Moscow: Publishing center "Academy", 2005, pp. 5-32.

[2] A. V. Sheviakov, "Physiological characteristics of the activities of plant operators as a factor of accidents," in Human Physiology, vol. 31, №. 5, 2005, pp. 135-141.

[3] S. I. Magid, E. H. Arkhipova and L. P. Musyca, "Modern requirements to vocational training in the conditions of reforming and development of power industry of the Russian Federation," in Energy saving and water preparation, № 6 (50), 2007, pp. 45-50.

[4] V. A. Mashin, "Mental workload, mental strain and functional States of the operators of control systems" in Problems of psychology, № 6, 2007, pp. 86-96.

[5] L. R. Zenkov, "Clinical electroencephalography (with elements epileptology). A guide for physicians," 5th ed., Moscow: Representors, 2012, pp. 25-38.

[6] R. A. Kudrin, "The influences of emotional and psychometric intelligence on the efficiency of operators' work at potentially dangerous objects," in Vestnik of Volgograd State Medical University, №. 3, 2011, pp. 62-65.

[7] E. A. Sergienko and I. I. Vetrova, "Test of John. Meier, P. Salovey, D. Caruso "Emotional intelligence" (MSCEIT V. 2.0)," Manual, Moscow: Institute of Psychology RAS, 2010, pp. 140-175. 